Atitude crítica e o sujeito de direitos das políticas (não) identitárias

Critical attitude and the subject of rights of (non) identity politics

\author{
Dhyego Câmara de Araujo ${ }^{1}$ \\ 1 Universidade Estadual de Ponta Grossa, Ponta Grossa, Paraná, Brasil. E-mail: \\ dhyegohirota@hotmail.com. ORCID: https://orcid.org/0000-0003-1611-0231.
}

Artigo recebido em 26/02/2018 e aceito em $1 \% / 08 / 2018$.

\title{
(cc) $\mathrm{BY}$
}

This work is licensed under a Creative Commons Attribution 4.0 International License 


\section{Resumo}

O presente artigo busca analisar dois possíveis modos de compreensão da identidade no direito, aqui chamados de metafísica da identidade e identidade-acontecimento. Aponta-se, em um primeiro momento, o regime de governamentalização da vida no cenário contemporâneo para, em seguida, verificar a concomitância entre as políticas (não) identitárias e a política dos direitos. Se os direitos protegem os sujeitos os enclausurando em uma identidade metafísica, também permitem instaurar identidadesacontecimentos como atitudes críticas frente às técnicas de governo. $\mathrm{O}$ argumento reside na compreensão da crítica arqueogenealógica foucaultiana como uma das formas de resistência às técnicas de governo dos direitos identitários, ao apontar para novas formas de "emancipação".

Palavras-chave: Sujeito de direitos; Identidade; Atitude Crítica; Arqueogenealogia; Política dos direitos.

\section{Abstract}

The present article aims to analyze two possible ways of understanding identity in Law, here called metaphysics of identity and identity-event. At first, it points the regime of government of life in the contemporary scenario, ant then, it intends to verify the concomitance of the (non) identity politics and the politics of rights. To protect the subjects they enclose them in a metaphysics of identity, but also they allow them to establish identities-events as critical attitudes towards the techniques of government. The argument lies in the understanding of Foucault's archeo-genealogical criticism as one of the forms of resistance to government techniques of identities rights, in pointing to new forms of "emancipation".

Keywords: Subject of rights; Identity; Critical Attitude; Archeo-genealogy; Politics of rights. 


\section{Introdução}

Uma das facetas do cenário jurídico-político contemporâneo refere-se aos movimentos de reivindicações de direitos radicados em traços identitários. Tomando como exemplos apenas algumas ações constitucionais no âmbito do Supremo Tribunal Federal (STF), o reconhecimento de determinados sujeitos como titulares de direitos dirige-se à identidade como seu ponto de fundamentação. Dentre tais exemplos, pode-se citar o reconhecimento jurídico de união estável formada por pessoas do mesmo sexo (BRASIL, 2011), o ingresso de pessoas negras nas universidades públicas (BRASIL, 2012) e no serviço público por meio de cotas (BRASIL, 2017), a posse de terras às comunidades quilombolas (BRASIL, 2018a), a possiblidade de retificação de nome e designativo de sexo (BRASIL, 2018b) nos registros públicos de pessoas (trans) ${ }^{1}$ etc.

De fato, a garantia desses direitos pelo STF alinha-se ao objetivo constitucional de construção de uma sociedade livre, justa e solidária, de tal sorte que o reconhecimento de determinados indivíduos como titulares de direitos implica, primeiro, na construção de uma identidade estabilizada, conforme expressão butleriana (BUTLER, 2016). Pode-se citar pelos menos dois pontos problemáticos desse panorama: o primeiro situa-se na cristalização de uma identidade tida como verdadeira, promovendo a formatação dos sujeitos em um único modo de ser; o segundo, e que decorre da anterior cristalização, refere-se à disposição dos indivíduos numa rede hierárquica, estabelecendo cortes no corpo coletivo entre aqueles mais aptos à titularidade dos direitos e aqueles marcados pela suspeição (ARAUJO, 2017).

Muito embora cientes da complexidade que envolve trabalhar com o tema das identidades no direito, o presente artigo não propõe uma análise detida a respeito dos percursos históricos de construções das subjetividades daqueles envolvidos nas ações constitucionais mencionadas. Busca-se, de outro modo, identificar pontos de contato delicados quando o direito é interpelado pelas políticas identitárias, tratando-se as situações aqui elencadas mais de tentativas de explicitação do problema, do que o esgotamento teórico e prático das questões jurídicas relativas aos grupos específicos.

\footnotetext{
${ }^{1}$ A utilização da palavra "trans" entre parênteses se dá devido a compreensão e concordância com Flávia Teixeira (2013, p. 37), segundo a qual nenhum termo parece dar conta de exprimir a totalidade de experiências de pessoas (trans), de modo a sugerir a sua utilização entre parênteses pois entende que assim se "questiona a própria estabilidade da categoria" (TEIXEIRA, 2013, p. 36).
} 
A título de ilustração, percebemos tal situação na necessidade jurídica e política de se discutir a existência de arranjos familiares para além do padrão heteronormativo. De um lado, a naturalização heterossexual do parentesco (BUTLER, 2003) revela uma rede de diferenciações jurídicas entre pessoas mais aptas que outras a constituir famílias de acordo com sua identidade de gênero e orientação sexual. De outro, a integração jurídica promovida por tal reconhecimento acarreta distinção entre sujeitos nãoheterossexuais aptos a constituir família em face de outros inaptos. Vale dizer, o reconhecimento jurídico não se aplica da mesma maneira a um casal formado por dois homens cis homossexuais, a uma mulher (trans) com uma mulher cis, ou a uma travesti solteira que deseje adotar filhos.

Desse modo, o reconhecimento jurídico implica, também ele, em um novo sistema de hierarquias pela construção e formatação de um tipo de identidade metafísica da identidade ${ }^{2}$. Entretanto, essa integração metafísica das identidades no direito permitirá a constante problematização daquilo tido, momentaneamente, como sujeito de direitos apto a compor uma família, abrindo novos espaços para construção de novos titulares de direitos - identidade-acontecimento ${ }^{3}$. O desenrolar dessa tecnologia jurídica se dá nessa tensão entre proteção pela formatação e hierarquização dos indivíduos e a abertura para futuras rearticulações das políticas (não) identitárias.

Não raras vezes, essa estabilização das identidades é garantida por certos usos da história que buscam desvendar no passado o ponto fundacional desses sujeitos, garantindo, com isso, seja a sua proteção jurídica, seja a justificativa para

\footnotetext{
${ }^{2}$ Por tal expressão, conforme se demonstrará nas páginas seguintes, indicamos uma certa compreensão da identidade enquanto fenômeno fixo, autorreferente e, portanto, dotado de sentido em si mesmo. A metafísica da identidade indicaria um ente no qual estariam ancorados sob seus contornos uma ampla gama de sujeitos que guardariam entre si algo que lhes tornassem comuns e, assim, iguais. As proposições acerca de uma "identidade verdadeira" a partir de características que lhes fossem inatas e compartilhadas por todos irrestritamente se inscrevem nesse quadro normativo. É metafísico porque se reporta a uma concepção de identidade que negligencia o que há de construído, fabricado, formatado e, sobretudo, as singularidades existentes em cada construção.

3 De acordo com Castro (2016), há quatro sentidos para o termo "acontecimento" no pensamento foucaultiano. Podemos distinguir tais concepções entre acontecimento como "ruptura histórica", isto é, a novidade ou a diferença; "regularidade histórica", condizente com o próprio movimento daquela ruptura anterior tornar-se uma regularidade; "atualidade", no qual se privilegia as lutas e as forças que estão em jogo na constituição do presente; e o verbo "acontecimentalizar" (événementialiser), como método de trabalho histórico. Para ver mais, consultar Vocabulário de Foucault (2016). Na expressão aqui trabalhada identidade-acontecimento - privilegiamos o terceiro sentido empregado ao conceito, muito embora compactuemos com a ideia de que essas quatro concepções intercambiam entre si. Assim, lançaremos mais luz à compreensão de acontecimento como aquele que se enreda por entre lutas e estratégias e que, se entrelaça, por sua vez, ao conceito de atualidade. "Dito de outra maneira, nós estamos atravessados por processo, movimentos, de forças; nós não os conhecemos, e o papel do filósofo é ser, sem dúvida, o diagnosticador destas forças, de diagnosticar a realidade" (FOUCAULT apud CASTRO, 2016, p. 25).
} 
promoção/manutenção de exclusões. Ao analisarmos, por exemplo, o estabelecimento do critério jurídico do "marco temporal" para concessão do direito de posse de terra às comunidades quilombolas, verificamos um recurso à história direcionado à (des)legitimação de sujeitos de direitos com base numa construção de subjetividade metafísica ligada a uma temporalidade específica.

Antevendo os perigosos desdobramentos da cristalização de uma identidade verdadeira, já na década de 80 Foucault alertava para os riscos da formulação de direitos radicados em um traço identitário. Para o filósofo francês há três tipos de lutas ${ }^{4}$ no campo social: aquelas que se opõem às formas de dominação (étnicas, religiosas, raciais); aquelas que denunciam formas de exploração e que separam o indivíduo do que ele produz; e por fim, e aqui as que mais nos interessam, as que combatem toda essa rede de conexões existente entre o indivíduo e ele mesmo e que garantem, desse modo, sua submissão ao governo ${ }^{5}$ dos outros (FOUCAULT, 2014, p. 122). Trata-se, nesse caso, das lutas contra as variadas formas de sujeição que se dão por meio do estabelecimento de uma verdadeira identidade.

Ao detalhar os aspectos dessas lutas contra as formas de submissão governamentais, Foucault aponta que se trata menos de lutas por ou contra 0 "indivíduo" do que propriamente estratégias que se opõem ao que ele denomina por "governo pela individualização" (FOUCAULT, 2014, p. 122), cujos efeitos eventualmente podem ser propagados pelo direito. Nas palavras do arqueogenealogista,

Essa forma de poder se exerce sobre a vida quotidiana imediata, que classifica os indivíduos em categorias, designa-os por sua individualidade própria, liga-os à sua identidade, impõem-Ihes uma lei de verdade que lhes é necessário reconhecer e que os outros devem reconhecer neles. É uma forma de poder que transforma os indivíduos em sujeitos. Há dois sentidos para a palavra "sujeito": sujeito submisso ao outro pelo controle e pela dependência, e sujeito ligado à sua própria identidade pela consciência ou pelo conhecimento de si. Nos dois casos, essa palavra sugere uma forma de poder que subjuga e submete (FOUCAULT, 2014, p.123 - grifo nosso).

\footnotetext{
${ }^{4}$ A respeito da coexistência e implicação circular de tais lutas no espectro social, Foucault escreve: "É evidente que não se pode estudar os mecanismos de sujeição sem levar em conta suas relações com os mecanismos de exploração e de dominação. Mas esses mecanismos de submissão não constituem simplesmente o "terminal" de outros mecanismos, mais fundamentais. Eles mantêm relações complexas e circulares com outras formas" (FOUCAULT, 20114, p. 124).

${ }^{5}$ Ao consultar os dicionários históricos da língua francesa, o arqueogenealogista observa que o verbete "governar", anteriormente à sua significação político-estatal do século XVI, guardava uma grande variedade de sentidos possíveis, os quais gravitavam em torno da seguinte formulação: "nunca se governa um território, nunca se governa uma estrutura política. Quem é governado são sempre pessoas, são homens, são indivíduos ou coletividades" (FOUCAULT, 2008, p. 164).
} 
A atenção a esse aspecto governamental do direito não busca apontar para um ordenamento jurídico presidido por um ente de racionalidade com vistas à normalização - o que levaria a uma compreensão anti-foucaultina de um poder personalizado. Buscase, com isso, sinalizar que o direito é atravessado por práticas de governo capazes de gerenciar comportamentos identitários relacionados aos variados dispositivos de poder, manejando o Estado como seu instrumento, mas não se reduzindo a ele. No horizonte da biopolítica ${ }^{6}$ é o governo que operacionaliza o Estado, e não o contrário.

Segundo Ben Golder (2015), ao atravessar o campo jurídico o governo pela individualização tende a situá-lo em um quadro ambivalente. De um lado, amarra-se à categoria de sujeito de direitos, que passa a ter frente ao Estado e aos outros indivíduos uma série de direitos e obrigações recíprocos, por meio da exigência de demandas identitárias. Por outro, contudo, permite a instauração de práticas de sujeição múltiplas ao relegá-los a uma identidade reveladora de sua própria verdade, em torno da qual se articularão mecanismos de controle e regulação, mas que também conterão as possibilidades de suas rearticulações. Na perspectiva de Golder (2015), saem de cena os direitos como um fim último a ser buscado, para se colocarem em uma política.

Considerando o entendimento de Michel Foucault a respeito das práticas ascéticas no contexto desenhado pelo governo pastoral, Golder formula a sua concepção de política dos direitos como uma situação estratégica, que permite pensálos na imanência desse movimento de fechamento e enclausuramento das identidades, simultaneamente à sua rearticulação para novas formas de se conduzir e ser conduzido. Segundo Golder (2015, p. 2),

Rights emerge [...] not as an end in themselves but rather as a tatical means, as an opening to other forms of emancipation, rearcitulation, and struggle that is, as representing some form of political possibility, whereas hitherto they had merely represented a blockage, an obstacle, an ideological mystification, or an unhelpful displacement of political energies onto legalformalist terrain $^{7}$

\footnotetext{
${ }^{6}$ Por tal termo, queremos delimitar essa modalidade de poder que, segundo Foucault, teria surgido no século XVIII. Trata-se de uma tecnologia do poder que se dirige sobre a vida naquilo que possui de orgânico e biológico. Sua operacionalidade em torno da vida se dá segundo comandos de promoção e incitação, de proliferação e acumulação, mas no mesmo sentido, de constante normalização e controle. Isto é, a vida é, efetivamente, estimulada e fabricada de forma contínua, todavia, esse esforço constante no entorno de sua produção se dirige não a todo e qualquer tipo de vida, mas a formas delimitadas e específicas de manifestação no interior da população a ser regulada (FOUCAULT, 2010; 2011)

7 "Direitos emergem não como um fim em si mesmo, mas como um meio tático, como uma abertura para outras formas de emancipação, rearranjo e luta - isto é, como representando alguma forma de possibilidade política, enquanto até então eles tinham apenas representado um bloqueio, um obstáculo,
} 
O desenrolar deste artigo se fará entre duas tomadas de posições possíveis a respeito do que se entende por identidade no interior dessa política dos direitos, que aqui chamaremos de metafísica da identidade e de identidade-acontecimento. Tais modos de compreensão do fenômeno identitário servirão de chave interpretativa às concepções ligadas aos sujeitos de direitos, situados entre os processos de sujeição jurídica e seus movimentos de rearticulações e desestabilizações.

Sendo assim, buscaremos demarcar as diferenças entre esses dois modos de compreensão da identidade no direito, privilegiando a atitude crítica de Michel Foucault, que a compreende não como causa em si mesma, mas como efeito de um longo e infindável processo de relações de forças - como acontecimentos.

O argumento do artigo reside na compreensão da atitude crítica arqueogenealógica ${ }^{8}$ foucaultiana como uma das formas de resistência ao governo pela individualização, ao escavar realidades outras soterradas pela naturalização de uma metafísica da identidade, que aparece na atualidade como necessária. Por meio dela, relativizamos o absolutismo do presente ${ }^{9}$, permitindo o constante questionamento de “como não ser governado?" diante de práticas e métodos precisos e determinados. 0 recurso à história ${ }^{10}$, por tal viés, se inscreve nesse registro de resistência à operação

mistificação ideológica ou deslocamento inútil de energias políticas para o terreno legal-formalista" (tradução livre).

8 Por arqueogenealogia entende-se o neologismo criado a partir de duas atitudes críticas foucaultianas frente ao conhecimento, quais sejam, a arqueologia e a genealogia. Enquanto a primeira direciona-se às configurações discursivas nas quais emergem um determinado objeto do conhecimento, tal como o sujeito; a segunda dirige-se às práticas de poder que tais discursos se ligam para a fabricação, formatação e regulação desses mesmos sujeitos. Sendo assim, a arqueologia demonstraria os critérios do dizer verdadeiro a respeito de determinado objeto, explicitando suas condições históricas de possibilidade e, portanto, o seu caráter contingente e precário. A genealogia, por sua vez, busca no recuo histórico verificar como esses discursos produziram verdades capazes de governar os sujeitos.

${ }^{9}$ Vale lembrar as lições de Paolo Grossi, para quem, por meio da história, desmistificamos aquilo que se apresenta como natural aos olhos do presente. Segundo o historiador do direito, a leitura histórica crítica "[...] retira o caráter absoluta das certezas de hoje, relativiza-as pondo-as em fricção com certezas diferentes ou opostas experimentadas no passado, desmitifica o presente, garante que sejam analisadas de modo crítico, liberando os fermentos atuais da estática daquilo que é vigente e estipulando o caminho para a construção do futuro" (GROSSI, 2004, p. 26).

${ }^{10}$ Em sua análise a respeito das contribuições de Foucault para os estudos elaborados no campo da história do direito Ricardo Marcelo Fonseca explica que "[...] para se entender o que é válido ou verdadeiro em determinada época, há que se historicizar os critérios de busca desta validez (e desta verdade), há que se perquirir as regras de funcionamento que são específicas de um determinado discurso para se definir o que é, assim, válido/verdadeiro. Foucault polemiza, portanto, contra as tentativas de "eternização" dos conceitos - e, portanto, da "eternização" das instituições e das formas de se apropriar os discursos. E aqui há um sinal importante para os juristas, na medida em que o conhecimento do direito em geral, na busca da estabilidade, tende fortemente a "eternizar" conceitos e instituições. O jurista, de fato, tem, em geral, uma dificuldade em relativizar/enquadrar seus conceitos, tendendo a gravá-los com uma trans-temporalidade, como se tivessem sido forjados fora de uma tempo-espaço determinado [...] (FONSECA, 2012, p. 136). 
metafísica deflagrada pelo direito, que constrói o sujeito de direitos como subjetividade coerente e estável, ao mesmo tempo em que, na concretude da vida, sujeita os corpos aos espaços de suspeita e normalização.

2. Por uma "ontologia histórica" do sujeito de direitos: tensões entre a metafísica da identidade e a identidade-acontecimento

Se pelas lentes construídas por Foucault é possível compreender as subjetividades como efeitos de um complexo heterogêneo de forças, a leitura mais usual - metafísica da identidade - se direciona à sua apreensão como algo preexistente às relações de poder, ontológico e fixo de sentido, porque portador de uma unidade e coerência que thes garante estabilização. Nesse sentido, o sujeito de direitos moderno se apresentaria como um dado material perfeitamente formado e, no entanto, abstrato e transcendental, considerado a priori de toda análise por ele suscitada.

Ao trabalhar com tais premissas, a metafísica da identidade se direciona a um reconhecimento ontológico de tais subjetividades, por meio do qual, a partir da conjugação de determinados atributos (raça, etnia, gênero, orientação sexual etc.), se garante a descoberta da verdade contida no ser. Este, ao se revelar - ou ter a sua verdade desvelada -, torna possível o fechamento da identidade sobre si mesma e o acionamento de um complexo de ações que se podem tomar a partir e contra ela.

Retomando a problemática levantada pela demarcação de terras quilombolas e indígenas, percebe-se que ainda vigoram discursos que apontam para a titularidade de direitos desde que comprovados os requisitos de uma verdadeira identidade, atrelando essa a critérios de temporalidade ou tradicionalidade. Por ser verdadeira e metafísica, em geral, essa identidade deve dispensar qualquer relação cultural com o entorno de seus territórios, na busca de uma real representação de um sujeito original portador de uma verdade intrínseca.

Cumpre destacar que, para Foucault (apud CANDIOTTO, 2010, p. 58), "em si mesma, a verdade é apenas um efeito - e o efeito de uma falsificação que nomeamos pela oposição entre o verdadeiro e o falso". A verdade está incluída nesse movimento de falsificação e esconde o seu caráter de "imposição histórica, rarefeita e exterior que 
atua na produção de verdades interessadas" (CANDIOTTO, 2010, p. 58), para figurar como uma unidade metafísica universalmente válida - como a ideia de um sujeito de direitos abstrato e universal, que ignora o seu acontecimento em uma realidade concreta atravessado por marcadores de gênero, classe, etnia etc.

Trata-se de concepção identitária fortemente atrelada à tradição humanista, que tende a presumir uma pessoa substantiva, portadora de inúmeras faculdades, desconsiderando a materialidade de seus próprios corpos (BUTLER, 2011) e como estes, ao adentrar no terreno da biopolítica, são fabricados na ordem jurídica como humanos ou não - perante o direito.

No desenrolar dessa elucubração metafísica, a identidade figura como uma ideia cujo sentido se mostra - ou se descobre - a partir do aguçamento do olhar para seus elementos. Tal concepção garante a existência de um sujeito a-histórico em virtude de uma essência que the é própria, perfazendo a ideia naturalizada de uma subjetividade universal de matriz neokantiana, cujo sentido se postergaria no tempo e no espaço na medida de sua própria natureza.

Em suma, através da metafísica da identidade, a verdade dos sujeitos de direitos não seria construída, mas descoberta. A partir de sua revelação, tanto a denúncia como a legitimação de seu leque de direitos dependeriam do teor semântico que permanecera guardado no invólucro de sua identidade agora demonstrada. Basta atentarmos para todo conteúdo relacionado àqueles movimentos identitários mencionados, que thes conferem um lugar específico no território, um modo de vida, uma forma de caráter. Se tais práticas se efetivam na fabricação de tais subjetividades, sua verificação não se dá pela descoberta ou revelação de algo já existente, mas sim pelo diagnóstico de quando e como acontecem.

Neste ponto reside a perspicácia de Foucault ao se debruçar sobre os modos de objetivação/subjetivação do humano, ou seja, de se perguntar acerca de "como um ser humano se transforma em sujeito" (FOUCAULT, 2014, p. 118). Assim, Foucault não trabalha naquele registro que apreende a identidade como esse dado pré-discursivo e preexistente às relações de poder. Ao examinar as suas condições de emergência, o autor busca historicizar e complexificar a ideia a respeito de como o humano "aprendeu a se reconhecer como sujeito" (FOUCAULT, 2014, p. 119). 
No quadro desenhado pela governamentalização da vida, retiram-se os contornos metafísicos da identidade ao considerá-la como fabricada pelas relações de poder, constituindo-se, por sua vez, como uma identidade-acontecimento. Foucault descreve o acontecimento

[...] não [como] uma decisão, um tratado, um reino, ou uma batalha, mas uma relação de forças que se inverte, um poder confiscado, um vocabulário retomado e voltado contra seus utilizadores, uma dominação que se enfraquece, se amplia e se envenena e uma outra que faz sua entrada, mascarada. As forças que estão em jogo na história não obedecem nem a uma distinção nem a uma mecânica, mas ao acaso da luta (FOUCAULT, 2012, p. 72).

Tem-se aqui não mais uma ambientação que parte de um sujeito dotado de uma identidade pressuposta, mas sim dispositivos que atuam na constituição, fabricação, formatação e regulação dessas identidades. Foucault, na trilha genealógica de Nietzsche, empreende uma analítica do poder radicalmente comprometida com a história, ao se perguntar a respeito das condições efetivas que possibilitaram o aparecimento de determinados tipos de sujeito, a exemplo do louco como doente mental no final do século XVIII (FOUCAULT, 2008) e do homossexual como desviante sexual no século XIX (FOUCAULT, 2011).

Para a identidade-acontecimento a verdade permanece a ocupar essa espécie de nó fundamental de sua formulação, contudo, não guarnece mais o que há de essencial na subjetividade, "'o aquilo mesmo' de uma imagem exatamente adequada a si" (FOUCAULT, 2012, p. 58). Representa, por sua vez, aquilo que aparece como visível, sendo essa visibilidade efeito de práticas discursivas emaranhadas nas estratégias de poder; a verdade, neste contexto, torna-se invenção ${ }^{11}$ (FOUCAULT, 2002, 14; 2012, p. 59).

Tanto na metafísica da identidade como na identidade-acontecimento, duas noções estão implicadas de maneira crucial, quais sejam, o sujeito e sua verdade. Se na primeira a verdade representa a própria essência e natureza mesma do sujeito, aquilo

\footnotetext{
${ }^{11}$ Quando utiliza o termo "invenção"11, Foucault o retira da obra nietzschiana, afirmando que, se por um lado Erfindung se trata de uma ruptura, por outro, diz respeito "a algo que possui um começo baixo, mesquinho, inconfessável" (FOUCAULT, 2002, p. 15). Conforme Foucault, no vocabulário nietzschiano, a invenção, Erfindung, ocuparia local de oposição à origem, Ursprung. Se a origem é a busca pela metafísica da identidade, a invenção se dá como "resultado do jogo, do afrontamento, da junção, da luta e do compromisso, entre os instintos. É porque os instintos se encontram, se batem e chegam, finalmente ao término de suas batalhas, a um compromisso, que algo se produz" (FOUCAULT, 2002, p. 16).
} 
que se recolhe por entre suas entranhas de modo a indicar sua realidade ontológica, na identidade como acontecimento, o sujeito surge como efeito de relações de poder-saber que $o$ atrelam a uma verdade histórica.

Importa mencionar que a identidade na economia do pensamento foucaultiano surge apenas como tema subjacente àquele que seria, de acordo com o próprio autor, "o tema geral de suas pesquisas": o sujeito (FOUCAULT, 2014, p. 118). A preocupação com o sujeito aparecerá, todavia, matizada segundo três domínios distintos, irredutíveis entre si, mas em implicação constante. Em entrevista concedida a Dreyfus e Rabinow, Foucault aponta tal propósito:

Três domínios da genealogia são possíveis. Primeiro, uma ontologia histórica de nós mesmos em relação à verdade através da qual nos constituímos como sujeito de saber; segundo, uma ontologia histórica de nós mesmos em relação ao campo de poder através do qual nos constituímos como sujeitos de ação sobre os outros; terceiro, uma ontologia histórica em relação à ética através da qual nos constituímos como agentes morais (DREYFUS, RABINOW, 1995, p. 262).

A ontologia histórica do presente serve de porta de entrada à compreensão dos movimentos identitários em sua relação com o direito, uma vez que permite retirar do sujeito de direitos seus aspectos metafísicos e apresentá-lo ao modo do acontecimento: construído segundo as marcas das singularidades de gênero, etnia, classe etc. Compreender o sujeito de direitos em sua realidade efetiva e não a partir de uma abstração jurídica permite-nos diagnosticar em quais estratégias de governo pela individualização o direito se insere.

É no interior das análises acerca da temática do governo, por sua vez, que pode ser situada a noção de "atitude crítica" desenvolvida por Foucault aliada ao seu empreendimento de uma "ontologia histórica" de nós mesmos. Na conferência "Qu'estce que la critique?" proferida em 1978 na Société de Philosophie, o filósofo busca responder tal questionamento, partindo da articulação entre crítica e Aufklärung.

Conjugando o problema da crítica em Kant - que pergunta pelos limites da razão naquilo que ela pode conhecer - com os desdobramentos decorrentes do Esclarecimento, Foucault afirma que tais formulações deveriam ser postas de outra maneira. Para ele, a pergunta deveria girar em torno da suspeita em relação a quais excessos de poder, ou seja, a qual governamentalização - por mais racionalmente 
justificada - a razão, ela própria, não teria sido historicamente responsável (FOUCAULT, 1978, p. 8). Nas palavras de Foucault:

[...] O que se busca então não é saber o que é verdadeiro ou falso, fundamentado ou não fundamentado, real ou ilusório, científico ou ideológico, legítimo ou abusivo. Procura-se saber quais são os elos, quais são as conexões que podem ser observadas entre os mecanismos de coerção e elementos de conhecimento, quais jogos de emissão e de suporte se desenvolvem uns nos outros, o que faz com que tal procedimento de coerção adquira a forma e as justificações próprias a um elemento racional, calculado, tecnicamente eficaz etc (FOUCAULT, 1978, p. 13-14).

De acordo com Candiotto (2010, p. 113), “a atitude crítica atua como limite das artes de governar impelindo sua modificação embora jamais seu desaparecimento". Enquanto para Kant, o esclarecimento correspondia ao processo de saída do homem da condição de menoridade - sob o governo de um outro, diria Foucault -, a atitude crítica apresenta-se como manifestação refletida da vontade de não ser governado, instaurando uma identidade-acontecimento diante das formatações de um único modo de vida proposto pela metafísica da identidade. Assim, a crítica foucaultiana aproximase, de alguma maneira, da definição kantiana das Luzes naquilo que se refere ao seu caráter "emancipatório" (aspecto desenvolvido no próximo item), contudo, tais conceitos são estendidos a domínios que excedem a perspectiva do filósofo alemão.

Ao compreender o valor da atitude crítica foucaultiana, compreende-se, por conseguinte, a relevância do empreendimento de uma "ontologia histórica" do presente em seu pensamento. Se a crítica busca impor ao poder o questionamento de como não ser governado, a "ontologia histórica" do presente faz-se crítica ao investigar os vínculos existentes entre as práticas de sujeição e os discursos de saber, bem como os jogos de reciprocidade e os pontos de apoio existentes entre eles. Em suma, pode-se dizer que

a crítica é o movimento pelo qual o sujeito se dá o direito de interrogar a verdade sobre seus efeitos de poder e o poder sobre seus discursos de verdade. [...] A crítica teria essencialmente por função o desassujeitamento no jogo do que se poderia chamar, em uma palavra, a política da verdade (FOUCAULT, 1978, p. 5).

Deste modo, o nível de análise da crítica foucaultiana sinaliza para os procedimentos de problematização filosófica do próprio autor, os quais inspiram o presente trabalho: a arqueologia e a genealogia.

Se uma das tarefas da crítica consiste em descrever o nexo de poder-saber que permite a apreensão daquilo que constitui historicamente a aceitabilidade de um 
sistema, seja este o sistema da sexualidade, do gênero, da etnia etc., a própria arqueologia apresenta-se como atitude crítica frente às positividades ${ }^{12}$ que se tornaram visíveis. Isto é, o empreendimento arqueológico busca demonstrar que as modalidades identitárias contemporâneas não são fenômenos necessários, por mais familiares que nos possam parecer.

O que se pretende explicitar, em verdade, são as condições de sua aceitabilidade em determinado momento histórico. A demonstração do seu caráter contingente, a partir de configurações discursivas ${ }^{13}$ que as tornaram possíveis, retiraIhes de seus domínios de naturalidade, denunciando a arbitrariedade das sujeições jurídicas em razão de algum traço identitário que as encoberta pelo manto da suspeita.

Importa mencionar que, não raras vezes o recurso metafísico de uma identidade negra é utilizado para deslegitimar os avanços sociais promovidos pelas políticas de cotas, sob o argumento de que estas endossariam, pejorativamente, certa inferioridade desses sujeitos, tendo em vista não abrangerem outras identidades não negras. Tal argumento não se sustenta, senão a partir da absoluta ignorância de todos os processos históricos de construção de subjetividades negras sob as marcas dos acontecimentos da escravidão, de segregações pontuais e de exclusões sistemáticas. Sobre isso, Davis (2016) é certeira ao pontuar que os regimes de exploração de classe não apenas distinguiram radicalmente sujeitos brancos e negros, como também sujeitaram de maneira diversa, e mais perversa, as mulheres negras em relação aos homens negros.

Por outro lado, a ambivalência dos direitos se faz eloquente, quando ações afirmativas são implementadas e disso emergem outras hierarquias, a exemplo das comissões organizadas para deliberação e julgamento da raça dos concorrentes

\footnotetext{
12 É de Paul Veyne a aparentemente controversa afirmação a respeito de Foucault: "É o primeiro historiador a ser completamente positivista" (VEYNE, 2014, p. 239). Ao dizer isso, Paul Veyne não está circunscrevendo o arqueogenealogista no campo da historiografia do positivismo, mas apontando para a singularidade de que, em seu modo de filosofar, Foucault não pressupõe a existência do objeto que está sob análise. Ao assim proceder, longe de se comportar como um historiador positivista, Foucault lança luz às condições que tornaram possível o surgimento desse objeto como positividade que ganha realidade (a identidade como positividade, por exemplo). Em razão disso, em seus textos o poder qualifica-se muito mais pelos seus efeitos positivos e produtivos do que negativos e repressores, característica que percorre toda a feitura do presente trabalho. Para mais detalhes sobre o positivismo historiográfico, conferir: FOSNECA, Ricardo Marcelo. Positivismo, "Historiografia Positivista" e História do Direito. In: Introdução teórica à história do direito. Curitiba: Juruá, 2012, p. 39-66.

${ }^{13}$ Segundo Foucault, o arqueólogo se dirige "ao espaço geral do saber, a suas configurações e ao modo de ser das coisas que aí aparecem, define sistemas de simultaneidade, assim como a série e as mutações necessárias e suficientes para circunscrever o limiar de uma positividade nova (FOUCAULT, 1996, p. 12).
} 
aprovados via política de cotas, em evidente manifestação de vigilância e controle desses sujeitos, tidos como suspeitos em sua autodesignação.

Diante de tais ambivalências, a realização de uma "ontologia histórica" do presente dispensa a explicação das singularidades - negros, mulheres, povos tradicionais, pessoas LGBTI etc. - com base em um princípio de unidade e de identidade. Ao contrário, ao negar a metafísica de uma identidade autorreferente, busca-se estabelecer uma rede estrutural que procura dar conta dessa singularidade como efeito de uma multiplicidade de relações de forças. Para o filósofo, o "importante é que não se trata em tais análises de reconduzir a uma causa um conjunto de fenômenos derivados, mas de colocar em inteligibilidade uma positividade singular no que ela tem justamente de singular" (FOUCAULT, 1978, p. 17).

Assim, não haveria como cercar discursivamente qualquer forma identitária do modo como as apreendemos hoje sem o quadro explicativo-normativo que as achatam, delimitando-as em termos jurídicos, médicos, religiosos, psicológicos, antropológicos, morais etc. Por tal perspectiva, afasta-se a noção de uma identidade coerente e estabilizada em si mesma, em nome de uma construção histórica que se dá de acordo com o que chamamos de identidade-acontecimento. Corroborando o argumento neste artigo defendido, Márcio Alves Fonseca (2008, p. 250) explica que, para Foucault, podese chamar de acontecimento "a irrupção de uma singularidade não necessária que, de algum modo, continua a nos atravessar", e que, sob o olhar arqueológico, torna-se possível sua apreensão.

A arqueologia foucaultiana ao se direcionar à grade de inteligibilidade que permite a apreensão do sujeito em termos de singularidade histórica, refere-se, ela mesmo, a uma atitude crítica, na medida em que aponta para o caráter histórico, precário e contingente das formas identitárias do presente. Desse modo, na esteira da crítica arqueológica somos levados à denúncia dos processos de sujeição decorrentes das próprias práticas de saber formuladas sobre os sujeitos.

Neste ponto, a análise arqueológica complementa-se ao procedimento genealógico. A genealogia refere-se ao tipo de compreensão de determinada positividade - as mulheres, por exemplo, em análise genealógica feita por McLaren (2016) - a partir de uma restituição histórica das condições de aparecimento dessa singularidade enquanto resultado de múltiplos elementos determinantes (FOUCAULT, 
1978 , p. 17). Se a arqueologia faz irromper junto aos quadros normativos do sujeito a fragilidade da própria verdade que o sustenta, a genealogia percorre o engendramento dessas positividades, acentuando quais as relações de poder que condicionaram a sua construção, a fim de constatar de que modo os sujeitos são modelados - pelas marcas da suspeita - no presente.

Trata-se, portanto, de um recurso histórico com vistas à atualidade, onde a "ontologia de nós mesmos" encontra sua pertinência. A atitude crítica genealógica mostra-se relevante na medida em que explicita o que, no presente, comporta, a respeito dos sujeitos, as marcas desses acontecimentos. Em outras palavras, trata-se de identificar na atualidade os registros desses eventos que são passados, mas que continuam a nos atravessar.

Em suma, a arqueologia e a genealogia, percebidas como atitudes críticas, permitem questionar de que modo "os efeitos de coerção próprios a essas positividades podem ser não dissipados, por meio de um retorno ao destino legítimo do conhecimento e por meio de uma reflexão sobre o transcendental que o fixa, mas invertidos ou desdobrados no interior de um campo estratégico concreto" (FOUCAULT, 1978 , p. 18-19). Dito de outra maneira, a arqueogenealogia nos conduz ao problema de saber como seria possível opor, relativamente aos efeitos de coerção dessas subjetividades uma atitude capaz de criar pontos que não sejam perpassados inteiramente pela sujeição governamental. Trata-se de pensar de que modo, frente aos poderes que efetivam o "governo da vida", seria possível opor uma decisão de não ser governado.

Ao nos lançarmos à compreensão da constituição de um sujeito, guiados pelo pensamento foucaultiano, o fenômeno identitário afasta-se de sua inscrição em termos de uma ontologia metafísica, e se instaura enquanto acontecimento, isto é, como uma configuração que se dá no interior de práticas de governo. Se a identidade aparece como fixa e estável, trata-se apenas do efeito desse longo e ardiloso processo que apaga os rastros de sua construção, mas cujo diagnóstico é possível pela atitude crítica arqueogenealógica (FOUCAULT, 2012, p. 55-86; BUTLER, 2016, p. 69, 173). A este respeito, escreve Foucault:

Ora, se o genealogista tem o cuidado de escutar a história em vez de acreditar na metafísica, o que é que ele aprende? Que atrás das coisas há "algo inteiramente diferente": não seu segredo essencial e sem data, mas o 
segredo que elas são sem essência, ou que sua essência foi construída peça por peça por figuras que lhe eram estranhas. (FOUCAULT, 2012, p. 58).

Não se vislumbra aqui a compreensão total de uma idealidade abstrata, "como se as palavras tivessem guardado seu sentido, os desejos sua direção, as ideias sua lógica" (FOUCAULT, 2012, p. 55). Na esteira desse modo de pensar, não haveria uma identidade perfeitamente acabada, à qual se poderia ter acesso, bastando, para tanto, um ajuste metodológico plenamente eficaz na descoberta de sua verdade. Trata-se, por tal perspectiva, de verificar as técnicas articuladas pelo direito na sua relação com as demandas identitárias, de modo a apontar a seletividade jurídica ao promover a materialização daqueles que merecem sua proteção, bem como daqueles ininteligíveis (BUTLER, 2011) para as lentes do direito.

A leitura arqueogenealógica da identidade-acontecimento pretende, desse modo, desmistificar o caráter essencial, permanente e natural das subjetividades, permitindo explicitar as relações de força que fabricam os sujeitos de direitos em sua realidade concreta e o modo como nós o compreendemos hoje. Se o sujeito de direitos se apresenta de maneira metafísica, o empreendimento arqueogenealógico feito por Michel Foucault é capaz de desvendar os meandros de produção das diversas formas identitárias, na medida em que faz proliferar a multiplicidade de eventos que concorreram na sua constituição histórica, bem como engendraram procedimentos de suspeita e exclusão.

3. Atitude crítica e arqueogenealogia: a política dos direitos diante da governamentalização da vida

Em linhas gerais, de acordo com o arqueogenealogista francês, a atitude crítica designa o surgimento na Europa ocidental dos séculos XV e XVI de "uma certa maneira de pensar, de dizer, igualmente de agir, de uma relação com o que existe, com o que sabemos e fazemos, uma relação com a sociedade, com a cultura, com os demais (FOUCAULT, 1978, p. 1-2). Analisando as práticas de condução das condutas/sujeição dos sujeitos, o filósofo pôde verificar, em relação a elas, as contracondutas subjetivação ética dos sujeitos - expressadas pela atitude crítica. 
Seguindo o que explica o próprio Foucault,

O termo "conduta" com seu próprio equívoco é, talvez, um dos que permitem melhor apreender o que há de específico nas relações de poder. A "conduta" é, ao mesmo tempo, o ato de "conduzir" os outros (segundo mecanismos de coerção mais ou menos estritos) e a maneira de se comportar em um campo mais ou menos aberto de possibilidades. 0 exercício do poder consiste em "conduzir condutas" e em arranjar a probabilidade (FOUCAULT, 2014, p. 133).

Intrinsecamente relacionada ao processo de governamentalização da vida a atitude crítica representa, frente ao imperativo de governo das condutas dos indivíduos, a pergunta consistente em "como não ser governado?". Como não ser governado desta ou daquela maneira, em razão de determinados princípios, com vistas a atingir certos objetivos e por meio de procedimentos específicos.

A atitude crítica, como visto, reside num feixe de relações que articula poder, verdade e sujeito diante das tecnologias de governo e que faz da "ontologia histórica" do presente uma forma de resistência. Se, de um lado, a sujeição da subjetividade constitui efeito da governamentalidade, de outro, a atitude crítica propõe uma nova política da verdade (FOUCAULT, 1978, p. 5), consistente na formulação de novos modos de subjetivação pelo direito. Essa nova política da verdade que surge na dinâmica existente entre as contracondutas e as práticas de governo se articula àquilo que Ben Golder denominou por ambivalência dos direitos. De acordo com o autor,

Foucault deploys rights as a form of critical counter-conduct, insisting that rights cannot help but disclose immanent possibilities for critique and rupture the sphere of action of subjects (as well as performatively bring new worlds and communities into being). But at the same time they can also be the conduit, or the vehicle, for relations of power that constitute those very subjects and communities in particular ways and hence reinscribe them within existing forms of power, of recuperanting and domesticating the political challenges they might pose ${ }^{14}$ (GOLDER, 2015, p. 91).

Desse modo, as lutas (não) identitárias travadas no campo do direito passam a ocupar esse local ambivalente, ambivalência esta relativa ao próprio fenômeno identitário. Tomemos, por exemplo, a problemática levantada pelo casamento de

\footnotetext{
14 “Foucault desdobra direitos como uma forma de contra-conduta crítica, insistindo que os direitos não podem deixar de revelar possibilidades imanentes de crítica e romper a esfera de ação dos sujeitos (assim como performativamente trazem novos mundos e comunidades para o ser). Mas, ao mesmo tempo, eles também podem ser o conduto ou o veículo para relações de poder que constituem esses sujeitos e comunidades de formas particulares e, portanto, reinscrevê-las dentro das formas de poder existentes, recuperando e domesticando os desafios políticos que podem representar" (tradução livre).
} 
pessoas do mesmo sexo. De um lado, o seu reconhecimento e garantia representam um avanço nas pautas dos movimentos LGBTI, ao atribuir às relações formadas por pessoas do mesmo sexo estatuto jurídico igual ao daquelas constituídas por pessoas de sexo diferente. Entretanto, ao adentrar o espectro do poder, o casamento não heterossexual torna-se também elemento de diferenciação, capaz de conferir legitimidade ou ilegitimidade entre as múltiplas formações familiares, funcionando como catalizador da escala de valores sexuais (MISKOLCl, 2007; GOLDER, 2015, p. 102).

Vemos que no pensamento foucaultiano a crítica está menos relacionada à "pesquisa pela legitimidade dos modos históricos de conhecer" de matriz neokantiana, do que propriamente à tentativa de verificar conexões entre mecanismos de coerção e formas de conhecimento. Trata-se, portanto, de abordar a questão pelo viés da acontecimentalização (FOUCAULT, 1978, p. 13). De acordo com Foucault, a pergunta deveria ser formulada nos seguintes termos:

[...] como a indissociabilidade do saber e do poder no jogo das interações e das estratégias múltiplas pode induzir ao mesmo tempo singularidades que se fixam a partir de suas condições de aceitabilidade e um campo de possibilidades, de aberturas, de indecisões, de retornos e de deslocamentos eventuais que os tornam frágeis, que os tornam impermanentes, que fazem desses efeitos dos acontecimentos nada mais, nada menos que acontecimentos? (FOUCAULT, 1978, p. 18).

Se a atitude crítica sinaliza para esta relação entre sujeito, poder e verdade no quadro da governamentalização da vida, a construção e modulação de identidadesacontecimento apontam, por sua vez, para as práticas de contraconduta correlatas a esse processo contínuo de suspeita e sujeição. A identidade-acontecimento figura, nesse sentido, como uma invenção, como essa irrupção de uma verdade cuja insígnia não traduz a essência do ser, mas a sua fabricação contínua. Assim, muito embora o sujeito de direitos apareça - de maneira exponencial - como uma forma perfeitamente acabada em virtude de sua abstração, o modo de atuação do direito junto aos sujeitos revela um longo processo de invenções de subjetividades cuja materialidade do corpo determinará a sua humanidade e, portanto, a sua condição de portador de direitos (BUTLER, 2009; 2011).

Comentando a noção de crítica no arcabouço teórico foucaultiano, Golder (2015) a encara mais como uma atitude afirmativa das possibilidades humanas do que uma instância de negatividade. Tal afirmação reside no fato de a crítica permitir, por 
exemplo, a abertura de possibilidades outras de vida - embora limitadas -, as quais foram esquecidas ou solapadas quando formações sociais e políticas contingentes ganharam contornos de naturalidade. Nas palavras do autor,

[...] It is on this affirmative dimension of Foucault's critical project - as represented in both archeology and genealogy - that the possibility and viability of counter-conducts rests. That is to say, it is precisely by virtue of the fact that concepts, institutions, practices, and indeed, even identities are not susceptible of one final and determinative meaning, but rather present themselves as unstable opportunities for re-articulation, reinvestment and countermobilization, that elements of forms of government can be appropriated to radically different ends ${ }^{15}$ (GOLDER, 2015, p. 58 - grifo nosso).

Se, conforme afirma Ben Golder (2015), a noção de contraconduta é peça essencial para a construção de uma política dos direitos em Michel Foucault, tal compreensão vai de encontro com a afirmação do próprio filósofo francês ao erigir a atitude crítica como um movimento de resistência frente às práticas do governo. 0 direito como modalidade de contraconduta crítica apresenta-se, desse modo, marcado por um movimento ambivalente ao tratar de questões relacionadas às políticas das identidades: junto ao fechamento e regulação das identidades, o direito pode servir de instrumento de ampliação, extensão e proteção das esferas de atuação desses sujeitos que necessitam a todo momento reafirmar a sua condição de titularidade de direitos.

A ambivalência jurídica se evidencia quando pensamos a trajetória de pessoas (trans) no âmbito do STF a partir da recente conquista do direito de modificação de registro civil sem prévia realização de cirurgia ou emissão de laudo pericial psicológico. Por um lado, verifica-se um inegável avanço na despatologização de tais sujeitos, mas por outro, tal garantia não pode representar o afastamento de toda uma rede de cuidados médicos e psicológicos direcionados a pessoas (trans), cujas vidas foram construídas sob a marca do estigma, da exclusão, da doença e da suspeita. Despatologizar, nesse sentido, deve implicar na contínua efetivação de práticas de atenção à saúde, mas estas, por sua vez, devem se voltar menos a mecanismos de normalização e controle e mais a procedimentos de cuidado.

15 “[...] É nesta dimensão afirmativa do projeto crítico de Foucault - representado tanto na arqueologia como na genealogia - que reside a possibilidade e viabilidade das contra-condutas. Ou seja, é precisamente em virtude do fato de que conceitos, instituições, práticas e até mesmo identidades não são susceptíveis de um significado final e determinante, mas que se apresentam como instáveis oportunidades de rearticulação, reinvestimento e contra-mobilização, de modo que os elementos dessas formas de governo podem ser apropriados para fins radicalmente diferentes [...]" (tradução livre). 
É evidente que ao tratar da relação do sujeito com o poder e a verdade nesses termos, Foucault os encara entrelaçados por uma rede de dispositivos cujo rompimento total e absoluto não se avista no horizonte das contracondutas. Em um tipo de análise que assume não existir nada fora do poder (EWALD, 1999), as esperanças emancipatórias são recolocadas em outros termos. Trata-se, conforme dito, não de uma instância de rejeição ou negação do objeto sob crítica - o direito sob o prisma do governo, o enclausuramento da identidade - mas, do contrário, de uma vinculação a um movimento de escavação e questionamento. A arqueogenealogia mostra-se capaz de afastar a auto evidência que repousa sobre tal objeto e fazer emergir fissuras significativas que nos levam a questionar aquilo que até então aparecia como natural.

Para Foucault, há sempre a possiblidade daquilo que está sob seu crivo conceitos, instituições, práticas, identidades - constituir-se de uma outra forma. Constituir-se de uma outra maneira do que estão conformadas no presente (GOLDER, 2015 , p. 154). Essa atitude revela a problemática foucaultiana em torno do "que é a crítica" sob a proposição de "como não ser governado" (FOUCAULT, OC).

Ao relativizar o caráter absoluto do presente, e entendê-lo enquanto um ponto em uma linha ${ }^{16}$ (GROSSI, 2005), vislumbramos as regras segundo as quais aquilo que se apresenta como verdade foram sedimentadas, mas que encobriram, para se fazer valer, outros modelos de veridiç̧ão ${ }^{17}$. De acordo com Ricardo Marcelo Fonseca (2012, p. 136), "só se explica a verdade (ou o que se entende como tal em determinada época) a partir

16 Paolo Grossi diz que o historiador do direito deve ser a consciência crítica dos demais juristas. Segundo o autor, essa função repousa na capacidade que o historiador possui de ver e demonstrar a provisoriedade e a precariedade das soluções jurídicas contemporâneas. Para o italiano, somos um ponto numa linha. Os juristas dogmáticos apenas conseguem enxergar o ponto, porque está inserido sensilvemente nela. 0 historiador, amplia o seu campo de visão para a linha na qual o ponto está localizado. Nas palavras do autor: "[...] Os diferentes momentos históricos, cada um dos quais representando uma maturidade autônoma dos tempos, não são ilhas separadas, mas pontos de uma longa linha, marcados por forças próprias e peculiares, as únicas que podem ser medidas e avaliadas. Mas sempre pontos, tão somente fragmentos de uma linha" (GROSSI, 2005, p. 43).

${ }^{17} \mathrm{E}$ aqui, Vainfas toca em um ponto fundamental para as atuais discussões jurídicas no que se refere ao casamento entre pessoas do mesmo sexo, quando sua recusa se fundamenta em algum argumento proveniente do campo religioso. De acordo com o historiador (VAINFAS, 1989, p. 10), "a postura da Igreja em face do matrimônio sempre fora problemática, e durante séculos permanecera o casamento como união profana, o "menor dos males", remédio para os que não conseguiam viver castos - era o que pregava São Paulo na Epístola aos Coríntios (I Cor., VII, 8). Até o século XII foram poucos, como Santo Agostinho, os que viram o casamento como sagrado, mas mesmo o insigne teólogo associava sacramento matrimonial com fidelidade e procriação, considerando impura a cópula conjugal em si”. Com a tomada do matrimônio pelo catolicismo, este passa a lhe ditar suas regras de funcionamento, ao mesmo tempo em que se transforma em um dos núcleos de intervenção da Igreja. É por meio da sacralidade do matrimônio que se pode controlar de perto a vida das famílias em sua convivência mais diária, colocando-se em prática todo um aparato de vigilância que se dirigia ao controle das consciências e dos comportamentos, e que se apoiava no sacramento da penitência e na confissão auricular (VAINFAS, 1989, p. 11-12). 
dos critérios - profundamente datados - em que é forjada. Toda verdade provém de um discurso que tem regras muito delimitadas (e nada metafísicas) para sua produção".

Se tal argumento funciona para deslegitimar toda e qualquer sujeição dessas subjetividades em atributos calcados em um sujeito abstrato e universal, também retira o sujeito de toda e qualquer fundamentação possível para a sua proteção e reconhecimento pelo direito. Não há uma universalidade dos direitos que possa servir de fundamento ao seu exercício, ao revés, de acordo com Golder (2015, p. 80), "the social and political practice of rights claiming itself establishes and contours the ground of rights. Rights are there to be seized ${ }^{18 \prime \prime}$. Nesse sentido, prossegue o autor $(2015$, p. 80)

Here the universality of rights, including obviously human rights, is an effect of, a product of, the investment made in rights by those who claim them - not a pre-existing characteristic of their being. Such a thinking of rights challenges the very topos of ground itself, which becomes not a pre-existing substance, but rather something wrought in and through the thoroughly political motions of rights claiming. Ground becomes an unstable and revisable aftereffect. ${ }^{19}$

A política da verdade instaurada entre as práticas de governo e as contracondutas constroem-se juntamente a uma política dos direitos, a qual se realiza, sempre, nesse registro ambivalente ao ser o direito interpelado pelos fenômenos identitários. Se há governamentalização da vida, há também abertura para novos tipos de relações do sujeito com sua verdade. Nessa concepção, segundo Golder (2015, p. 97), "[...] rights are a tool for political subjetcs to protect and advance their interests, to make a claim for recognition, and to expand the range of their actions ${ }^{20 "}$.

Tal concepção da política dos direitos converge com o modo que Allen (2015, p. 117) compreende as lutas por reconhecimento e os processos emancipatórios a partir do pensamento de Foucault e Butler. Segundo a autora, apesar de não se aventar a possibilidade de uma revolução, depois da qual estaríamos todos livres dos quadros normativos que nos governam, tais filósofos apostam em uma atitude crítica frente aos mecanismos de poder que os exploram naquilo que podem subvertê-los e revertê-los e

\footnotetext{
18 "A reivindicação social e política de direitos, por si mesma, estabelece e contorna os fundamentos dos direitos. Direitos devem ser apreendidos" (tradução livre)

19 "Aqui, a universalidade dos direitos, incluindo obviamente os direitos humanos, é um efeito, um produto do investimento feito em relação aos direitos por aqueles que os reivindicam - não uma característica préexistente de seu ser. Esse pensamento desafia o topos do próprio substrato teórico, que não se torna uma substância pré-existente, mas sim algo forjado completamente dentro e através dos movimentos políticos de reivindicação de direitos" (tradução livre).

20 "[...] os direitos são instrumentos para que sujeitos políticos protejam e promovam seus interesses, demandem por reconhecimento e ampliem o alcance de suas ações" (tradução livre).
} 
em sua instabilidade. Trata-se, portanto, de um paradoxo - ou da ambivalência dos direitos, como diria Ben Golder (2015). Para a autora, contudo, a posição de tais filósofos não é a de um niilismo passivo, nos instigando, ao contrário, a transformar essa situação aparentemente paralisante em uma "tensão produtiva [...] isto é, que defina a emancipação negativamente como a transformação do estado de dominação em um terreno móvel e reversível de relações de poder e que, desse modo, não se faça prisioneira de uma visão utópica isenta de relações de poder" (ALLEN, 2015, p. 117).

Compreender quais discursos são incitados e acionados para dizer a verdade sobre os sujeitos, nos auxilia no diagnóstico das malhas de controle e regulação em que se encontram amarrados sob sua marca identitária. Questionar as verdades construídas dentro do campo jurídico e confrontá-las em um jogo com outros discursos de verdade, permite-nos, por sua vez, a rearticulação e desestabilização do direito, de modo a rasurar seu tecido normativo. A demonstração, pela via arqueogenealógica, da própria governamentalização do direito nos aponta para os dispositivos que o informam diferente daquela idealização por ele reivindicada como pretensamente neutra, racional e igualitária.

É nesse movimento de fabricação, formatação e condução das identidades que o próprio direito pode revelar-se enquanto contraconduta crítica apontando para caminhos outros, tendo na arqueogenealogia via privilegiada em virtude de sua capacidade de escavar bem como relevar verdades antes soterradas. A atitude crítica como interjeição à governamentalização da vida implica nesse distanciamento da atualidade se perguntando, todavia, o que nela permanece cristalizado enquanto substância naturalizada.

Nos meandros das políticas (não) identitárias esse movimento de rearticulações, desestabilizações e lutas encontram, assim, na política dos direitos, uma aliada e ao mesmo tempo uma adversária, tal qual Foucault afirmara sobre a questão de "como não ser governado" diante das artes de governar. Se não se antevê no direito o caminho para a emancipação - talvez porque esta não se vislumbre em qualquer registro - a sua ambivalência nas relações com as identidades pode ser capaz de fazer irromper aberturas possíveis de práticas de "emancipação" ligadas, sempre e em estrita vizinhança, a práticas de governo pela individualização. 


\section{Considerações finais}

Pensar os direitos identitários no cenário marcado pela governamentalização da vida nos impõe constantemente uma série de questões: como formalizar juridicamente tais demandas quando o reconhecimento implica, também, sujeição governamental? Quais as atitudes críticas que se abrem para o pensamento jurídico quando nos deparamos sobre modos de pensar que prescindem de fundamentação (sobretudo aquelas ancoradas nos sujeitos)? Se a metafísica da identidade instaura mecanismos de hierarquização e exclusão de formas de vida diferentes daquela que seu contorno encerra, o que se aponta no horizonte é a sua rejeição total?

Tais questões percorreram toda tessitura deste artigo e, muito embora não tenham sido respondidas de modo absoluto, buscou-se em alguma medida, dispor de alguns instrumentos de análise à compreensão do cenário jurídico no tocante aos direitos (não) identitários. Ao pensarmos esses direitos em uma "ontologia histórica" do presente vemos transparecer, para além o seu reconhecimento, a construção de identidades-acontecimento.

Por identidade-acontecimento, quisemos mostrar que, no horizonte esquadrinhado pela governamentalização da vida, o ordenamento jurídico pode funcionar como objeto e, ao mesmo tempo, instrumento, desse poder capaz de instaurar subjetividades múltiplas no espectro da suspeita e normalização. Não há a declaração da existência de uma identidade coerente e estável, mas a fabricação, regulação e ordenação de identidades de maneira constante segundo regras específicas. Tal termo, entretanto, não apenas ressalta o caráter construído das subjetividades, como também joga luz para o sentido de precariedade e instabilidade que elas assumem nesse terreno de análise.

O que se descortina através da tensão entre a metafísica da identidade e a identidade-acontecimento revela o próprio caráter ambivalente dos direitos ao lidar com tais demandas. Os direitos, longe de se reportarem a uma situação futura, ocasião na qual seriam reconhecidos a toda coletividade, representam antes instrumentos para lutas atuais. Se não podem atuar sem que delimitem e enclausurem as subjetividades, possibilitam outras formas de "emancipação". 
Não se trata aqui do processo emancipatório tradicionalmente colocado pelas teorizações jurídico-políticas. Sob a ótica de Butler e Foucault, há que se estabelecer uma leitura da diferença para sua apreensão. Tomar o poder como constitutivo do real significa postulá-lo como intrinsecamente emaranhado às positividades que the constituem. A radicalidade de tal pensamento implica em considerar que as atitudes críticas de resistência ou de contraconduta frente ao governo se dão sempre no interior dos próprios mecanismos que as regula.

Assim, a "emancipação" que se esboça trata-se menos da garantia de um lugar para sujeitos livres e iguais (em absoluto), do que a certeza de que à compreensão das próprias demandas se coloca dentro de um quadro regulatório de governo pela individualização. A "emancipação" se dá, desse modo, mais pelo processo que pela síntese final, na medida em que sua construção se permeia sempre por resultados instáveis e precários: como acontecimentos.

Nesse cenário, a arqueogenealogia foucaultiana mostra-se eficaz em seus efeitos de contraconduta crítica. O esforço nesse recuo histórico-filosófico, na busca da compreensão das subjetividades como absolutamente dependentes dos quadros interpretativos em que foram inventadas, aponta para a precariedade do presente. Ao mesmo tempo, indica o soterramento de outras verdades sobre os sujeitos que foram esquecidas ao fazer prevalecer tal grade de inteligibilidade. A arqueologia demonstra-se apta a explicitar que a verdade sobre os sujeitos reside mais nas regras estabelecidas para o discurso verdadeiro do que em algum predicado escondido em sua essência. Por sua vez, o percurso genealógico nos coloca frente às técnicas de sujeição a que tais indivíduos foram submetidos de acordo com aquelas configurações discursivas. Diagnosticar a tecnologia de governo que atua atravessando o direito nos permite identificar a verdade por meio da qual este justifica sua atuação.

Em síntese, os direitos enquanto contraconduta crítica encontram aliado fundamental no procedimento arqueogenealógico. Desmistificar a abstração universal dos sujeitos de direitos nos possibilita realizar esse trabalho de diagnóstico sobre qual humano se materializa nos meandros da representação jurídica, e quais aqueles relegados aos espaços de suspeita. Assim, a denúncia permitida pelo mapeamento arqueogenealógico das políticas (não) identitárias no direito nos possibilita estabelecer, 
frente aos desígnios do governo das condutas, atitudes críticas como formas de resistência.

Referências bibliográficas

ALLEN, Amy. Emancipação sem utopia: sujeição, modernidade e as exigências normativas da teoria crítica feminista. (Tradução de Inara Luisa Marin, Felipe Gonçalves Silva e Ingrid Cyfer). Revista Novos Estudos 103, novembro de 2015, p. 115-132.

ARAÚJO, Inês Lacerda. Foucault e a crítica do sujeito. 2a ed. Curitiba: Editora UFPR, 2008.

ARAUJO, Dhyego Câmara de. Identidades sob suspeita: uma arqueogenealogia do sexo e do gênero no direito. 2017. 178f. Dissertação (Mestrado em Ciências Jurídicas). Universidade Federal do Paraná, 2017.

BRASIL. SUPREMO TRIBUNAL FEDERAL, ADPF 132. Relator: Min. Ayres Britto. DJ: 05/05/2011. Disponível em: $<$ http://www.stf.jus.br/portal/processo/verProcessoAndamento.asp?numero=132\&clas se $=A D P F \&$ codigoClasse $=0 \&$ origem $=J U R \&$ recurso $=0 \&$ tipoJulgamento $=M>$. Acesso em: 23/02/2018.

BRASIL. SUPREMO TRIBUNAL FEDERAL, ADPF 186. Relator: Min. Ricardo Lewandowski. DJ: 24/04/2012. Disponível em: $<$ http://www.stf.jus.br/portal/processo/verProcessoAndamento.asp?numero=186\&clas $\mathrm{se}=\mathrm{ADPF} \&$ codigoClasse $=0$ \&origem $=J U R \&$ recurso $=0 \&$ tipoJulgamento $=\mathrm{M}>$. Acesso em: 23/02/2018.

BRASIL. SUPREMO TRIBUNAL FEDERAL. ADC 41. Relator: Min. Roberto Barroso. DJ: 08/06/2017. Disponível em: $<$ http://www.stf.jus.br/portal/processo/verProcessoAndamento.asp?numero=41\&class $\mathrm{e}=\mathrm{ADC} \&$ codigoClasse $=0$ \&origem $=J U R \&$ recurso $=0$ \&tipoJulgamento $=\mathrm{M}>$. Acesso em: 23/02/2018.

BRASIL. SUPREMO TRIBUNAL FEDERAL, ADI 3239. Relator: Min. Cezar Peluso. DJ: 23/02/2018a. Disponível em: $<$ http://www.stf.jus.br/portal/processo/verProcessoAndamento.asp?numero=3239\&cla sse=ADI\&origem=AP\&recurso=0\&tipoJulgamento=M>. Acesso em: 23/02/2018.

BRASIL. SUPREMO TRIBUNAL FEDERAL, ADI 4275. Relator: Min. Marco Aurélio. DJ: 09/03/2018b.Disponível em: $<$ http://www.stf.jus.br/portal/processo/verProcessoAndamento.asp?incidente $=269137$ 1>. Acesso em: 23/02/2018. 
BUTLER, Judith. Problemas de gênero: feminismo e subversão da identidade. Tradução de Renato Aguiar. Rio de Janeiro: Civilização Brasileira, 2016.

. O parentesco é sempre tido como heterossexual? Cadernos Pagu [online], 2003, n. 21, pp. 219-260.

. Frames of war: when is life grievable. London and New York: Verso, 2009.

. Bodies that matter: on the discursive limits of "sex". London and New York: Routledge, 2011.

CANDIOTTO, Cesar. Foucault e a crítica da verdade. Belo Horizonte: Autêntica Editora; Curitiba: Champagnat, 2010.

CASTRO, Edgardo. Vocabulário de Foucault: um percurso pelos seus temas, conceitos e autores. Tradução de Ingrid Müller Xavier. 2a ed. Belo Horizonte: Autêntica Editora, 2016.

DAVIS, Angela. Mulheres, raça e classe. Trad. Heci Regina Candiani. 1a ed. São Paulo: Boitempo, 2016.

DREYFUS, Hubert; RABINOW, Paul. Michel Foucault: uma trajetória filosófica para além do estruturalismo e da hermenêutica. Rio de Janeiro: Forense Universitária, 1995.

EWALD, François. Un poder sin um afuera. In: Michel Foucault filosofo. (Traducción Alberto Luis Bixio). Barcelona: Editorial Gedisa, 1999.

FONSECA, Ricardo Marcelo. Introdução teórica à história do direito. Curitiba: Juruá, 2012a.

FONSECA, Márcio Alves da. Entre a vida governada e o governo de si. In: ALBUQUERQUE JÚNIOR, Durval Muniz de; VEIGA-NETO, ALFREDO; SOUZA FILHO, ALÍPIO DE (Org.). Cartografias de Foucault. Belo Horizonte: Autêntica Editora, 2008, p. 241-251.

FOUCAULT, Michel. História da Sexualidade - Volume 1: a vontade de saber. Tradução de Thereza da Costa Albuquerque e J. A. Guilhon Albuquerque. Rio de Janeiro: Graal, 2011.

. Michel. Les mots e les choses: une archeology des sciences humaines. Paris: Gallimard, 1996.

. A verdade e as formas jurídicas. Tradução de Roberto Cabral de Melo Machado e Eduardo Jardim Morais. Rio de Janeiro: NAU Editora, 2002.

. Em defesa da sociedade. Curso no Collège de France (1975-1976). Tradução de Maria Emantina Galvão. - 2a . ed. - São Paulo: Editora WMF Martins Fontes, 2010.

. Microfísica do poder. (Org. Roberto Machado). 25a ed. São Paulo: Graal, 2012. 
Ditos e escritos IV: estratégia, poder-saber. Tradução de Vera Lúcia Avellar Ribeiro. Manoel Barros da Motta (Org.) Rio de Janeiro: Forense, 2003

Ditos e escritos IX: genealogia da ética, subjetividade e sexualidade. (Org. Manuel Barros da Motta, trad. Abner Chiquieri). Rio de Janeiro: Forense Universitária, 2014.

. Segurança, Território, População. Curso no Collège de France (1976). Tradução de Eduardo Brandão. 1a ed. São Paulo: Martins Fontes, 2008.

O que é a crítica? Crítica e Aufklärung. Tradução do original Qu'est-ce que la critique? Critique et Aufklärung. Bulletin de la Societé françasise de philosophie. Vol. 282, n. 2, pp. 35-63, arv/juin 1990 (Conferência proferida em 27 de maio de 1978). Tradução de Gabriela Lafetá Borges e Revisão de Wander Flor do Nascimento, p. 1-29. Disponível em: http://portalgens.com.br/portal/images/stories/pdf/critica.pdf. Acesso em: 29/11/2016

GOLDER, Ben. Foucault and the politics of rights. California: Stanford University Press, 2015.

GROSSI, Paolo. O Ponto e a Linha: história do direito e direito positivo na formação do jurista do nosso tempo. Tradução de Mônica Sol Glik. Revista Sequência. n. 51, 2005, p. 31-45.

. Mitologias jurídicas da modernidade. Florianópolis: Fundação Boiteux, 2004.

MCLAREN, Margaret A. Foucault, feminismo e subjetividade. (Coleção Estrangeiros) São Paulo: Intermeios, 2016.

Miskolci, Richard. Pânicos morais e controle social: reflexões sobre o casamento gay. Cadernos pagu, n. 28, p. 101-128, janeiro-junho de 2007.

TEIXEIRA, Flávia do Bonsucesso. Dispositivos de dor: poderes que conformam as transexualidades. São Paulo: Annablume; Fapesp, 2013.

VAINFAS, Ronaldo. Trópico dos pecados: moral, sexualidade e inquisição no Brasil Colonial. Rio de Janeiro: Campos, 1989.

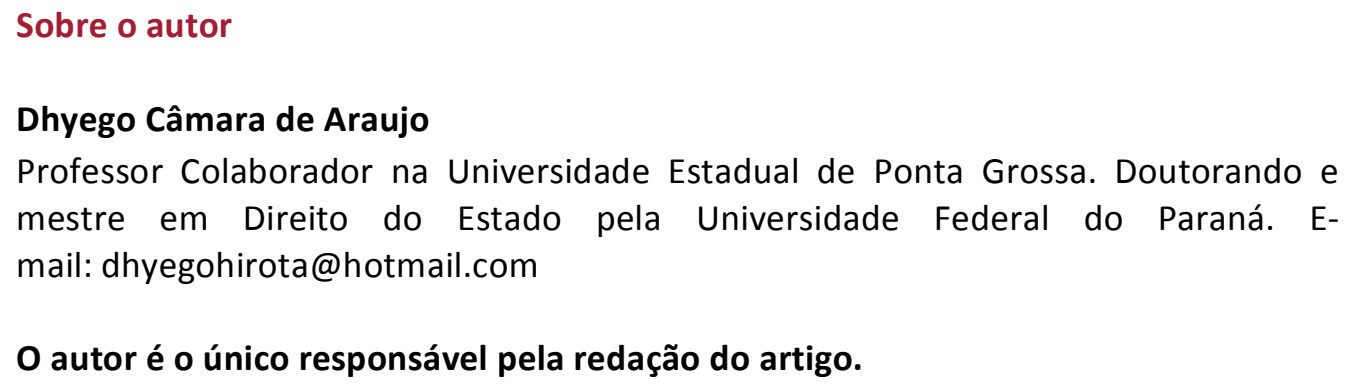

